\title{
O PROCESSO EDITORIAL NOS PERIÓDICOS E SUGESTÕES PARA A PUBLICAÇÃO
}

\section{JOURNALS' EDITORIAL PROCESS AND SUGGESTIONS TOWARDS PUBLICATION}

\section{Manuel Aníbal Silva Portugal Vasconcelos Ferreira}

Doutor em Business Administration pela Universidade de Utah, EUA.

Professor do Programa de Pós Graduação em Administração da Universidade Nove de Julho PPGA/UNINOVE.

E-mail: manuel.portugal@uninove.br (Brasil)

\section{Renata Canela}

Doutoranda pelo Programa de Pós Graduação em Administração da Universidade Nove de Julho PPGA/UNINOVE.

Professora nas Faculdades de Campinas - FACAMP.

E-mail: wausma@waus.com.br (Brasil)

\section{Cláudia Frias Pinto}

Doutoranda pela Escola de Administração de Empresas de São Paulo da Fundação Getúlio Vargas EAESP/FGV.

E-mail: claudia.frias.pinto@gmail.com (Brasil) 


\title{
O PROCESSO EDITORIAL NOS PERIÓDICOS E SUGESTÕES PARA A PUBLICAÇÃO
}

\section{RESUMO}

Muitos autores e, especialmente, os menos experientes e estudantes de doutorado, veem o processo editorial e a publicação como uma caixa-preta cheia de mistérios e misticismos. Neste artigo analisamos e discutimos o processo editorial. Entender o processo nas suas etapas e como interagir com revisores e editores ajudará os autores a organizar, escrever e trabalhar as suas pesquisas para aumentar a probabilidade de ter os artigos aceitos para publicação. Descrevemos o processo editorial e apresentamos algumas sugestões para melhor navegar no processo - algumas sugestões são relativamente óbvias e outras, sujeitas a maiores doses de subjetividade.

Palavras-chave: Processo Editorial; Publicação em Periódico; Revisores; Editores; Periódicos Científicos.

\section{JOURNALS' EDITORIAL PROCESS AND SUGGESTIONS TOWARDS PUBLICATION}

\begin{abstract}
Many authors and especially those less experienced ones and doctoral students perceive the editorial process and publishing as a black box full of mysteries and mysticisms. In this paper we analyze and discuss the editorial process. Understanding the process and its stages and how to interact with reviewers and editors will help researchers to organize, write and work their research to improve the probability of having their papers accepted for publication. We describe the editorial process and present some suggestions in order to better navigate the process - some suggestions are reasonably obvious and others entail greater subjectivity.
\end{abstract}

Keywords: Editorial Process; Publishing in Journals; Reviewers; Editors; Scientific Journals.

Revista de Gestão e Secretariado - GeSec, São Paulo, v. 5, n. 2, p 01-22, mai./ago. 2014. 


\section{INTRODUÇÃO}

A publicação de trabalhos científicos em periódicos é importante para os autores por diversas razões. Primeiro, significa a validação dos seus trabalhos, dado que os artigos publicados em periódicos com revisão pelos pares são considerados certified knowledge (Miller, 2006; Acedo, Barroso, Casanueva, \& Galán, 2006). Segundo, é pela publicação que se dissemina o novo conhecimento gerado (Bedeian, 2004; Gondim, 2004; Miller, 2006; Elson \& Brouard, 2012). Terceiro, a publicação é uma métrica importante de desempenho que as instituições avaliam, algumas premiam, e que contribui para a progressão profissional (Armstrong, 1997). Assim, não é estranho que vários autores, em diversas disciplinas, se tenham debruçado sobre diferentes facetas da publicação científica, focando aspectos como as dificuldades de publicação (Serra, Fiates \& Ferreira, 2008), as redes de coautoria (Barabási; Jeong; Néda; Ravasz; Schubert \& Vicsek, 2002; Moody, 2004; Acedo et al., 2006), o que fazer para aumentar a probabilidade de conseguir publicar (Moody, 2004; Sparrowe \& Mayer, 2011; Geletkanycz \& Tepper, 2012; Zhang \& Shaw, 2012), a rejeição (Gans \& Shepherd, 1994; Beyer, Chanove \& Fox, 1995; Byrne, 2000), as perspectivas dos revisores (Singh, 2003; Swanson, 2004) e dos editores (Radford, Smillie, Wilson, R. \& Grace, 1999; Pinho, 2005), os riscos à saúde da carreira do pesquisador (De Meis, Velloso, Lannes, Carmo \& De Meis, 2003), o produtivismo (Sguissardi \& Silva Jr., 2009), a relevância e rigor da produção científica em Administração (Mascarenhas, Zambaldi, \& de Moraes, 2011), as taxas de aceitação dos artigos nos periódicos (Sugimoto, Larivière, Ni \& Cronin, 2013), a revisão pelos pares (Armstrong, 1997; Byrne, 2000; Dahdouh-Guebas, Ahimbisibwe, Van Moll \& Koedam, 2003; Miller, 2006; Blackburn \& Hakel, 2006; Raelin, 2008) e a rejeição direta ou desk rejection pelos editores (Craig, 2010; Ahlstrom, 2010).

Neste artigo contribuímos para este debate sobre a publicação, o processo e a interação com revisores, focando especificamente dois componentes inter-relacionados. Primeiro, analisamos brevemente as etapas do processo editorial, ou o fluxo do artigo submetido, e, segundo, apresentamos um conjunto de "sugestões" sobre como ultrapassar com sucesso esse processo. Ainda que a nossa audiência-alvo sejam os estudantes de mestrado e doutorado, este artigo será útil a todos que pretendam submeter um trabalho a um periódico científico de Administração com revisão pelos pares. Assim, a intenção primeira deste artigo é trazer à luz e desmistificar o processo editorial. Este é um propósito relevante numa altura em que muitos acadêmicos criticam a academia 
que dizem dominada por uma lógica de "produtivismo" (ver, por exemplo, Barnett, Ault \& Kaserman, 1988; Frey, 2003; Rutledge \& Karim, 2009; Sguissardi \& Silva Jr., 2009), e pela pressão sobre os pesquisadores para publicar mais e em periódicos com impacto. Este artigo é, também, relevante para os estudantes que precisam publicar para cumprir os requisitos e as expectativas dos seus programas doutorais. Finalmente, é relevante para ajudar a entender o processo editorial. O processo editorial ainda está amplamente envolto em mitos que são efetivas barreiras à produção. No entanto, importa deixar expresso que não há grandes segredos para conseguir publicar e que alguns elementos são sempre fundamentais: fazer uma boa pesquisa, escrever de forma clara (Ragins, 2012), ter uma revisão da literatura coerente e que integre os trabalhos seminais com os novos desenvolvimentos (Reuber, 2010), escolher o periódico mais adequado para submeter o artigo e interagir de forma positiva com o editor e revisores (Bedeian, 2003; Levy \& Grewal, 2007; Ferreira, 2013b).

Este artigo está organizado em três partes principais. Na primeira, descrevemos o processo editorial, revelando o fluxo das etapas pelas quais o artigo passa quando submetido a um periódico até chegar ao desfecho final de aceite ou rejeição para publicação e analisamos apenas algumas das etapas. Na segunda parte, adotamos uma perspectiva mais didática, salientando alguns cuidados, ou sugestões, para os jovens autores. Concluímos com uma discussão breve apontando a importância de compreender melhor o processo para aumentar a qualidade da pesquisa e produtividade dos pesquisadores.

\section{O PROCESSO EDITORIAL}

Pesquisar e publicar não é tarefa fácil. Pesquisar tende a ser uma atividade bastante solitária do pesquisador com suas leituras, pensamentos, redação, tratamento dos dados, apresentações, revisões, rejeições. Uma atividade permeada mais por críticas que por louvores. E, fundamentalmente, a pesquisa exige enorme persistência, quando o estudo se desenvolve ao longo de anos. A resiliência, ou perseverança, é, assim, uma das características fundamentais do pesquisador prolífico que leva seu trabalho desde a fase de geração da ideia até a publicação em periódico.

A publicação de um trabalho de pesquisa em periódico envolve todo um processo que começa logo na fase de planejamento da pesquisa e só termina com a publicação do artigo. Este processo é genericamente semelhante em todos os campos de conhecimento, ainda que diferentes

Revista de Gestão e Secretariado - GeSec, São Paulo, v. 5, n. 2, p 01-22, mai./ago. 2014. 
disciplinas e diferentes periódicos tenham padrões que variam em função do tema e, até, do momento. Pesem todas as possíveis idiossincrasias disciplinares, podemos sumariar as principais etapas do processo editorial.

O processo editorial de avaliação e revisão tem por principal fundamento que o artigo científico necessita ser avaliado por outros pesquisadores (que designamos pares) como forma de verificação e legitimidade (Bedeian, 2004; Miller, 2006; Elson \& Brouard, 2012) antes de ser publicado. Evidentemente, este é um processo baseado na premissa de que os revisores são indivíduos competentes na área do artigo que avaliam, que são independentes, objetivos e que dedicam seu melhor esforço à avaliação. Outra premissa é que todo o processo decorre de forma anônima (Smith, 1998; Bedeian, 2003; Gondim, 2004; Kirschbaum \& Mascarenhas, 2009), em que nem o autor sabe quem são os revisores, nem os revisores sabem quem é o autor. Denomina-se, assim, revisão double blind - para sinalizar que os avaliadores desconhecem quem são os autores e os autores desconhecem quem são os avaliadores. $\mathrm{O}$ anonimato visa garantir que outros fatores não interagem na avaliação, não enviesando o resultado.

O processo editorial é, também, baseado na premissa de que os editores dos periódicos dedicarão o seu melhor esforço na avaliação inicial dos artigos que lhe são submetidos (designamos a avaliação inicial pelo editor de desk review), na busca dos revisores mais adequados para analisar cada um dos artigos e na análise dos pareceres dos revisores (Gondim, 2004). Novamente, esperamos que os editores sejam independentes, tratem os artigos recebidos com os padrões de anonimato pressupostos e busquem publicar os melhores artigos (com o rigor e a contribuição que se assume do conhecimento cientifico) (Bertero, 2007; Mascarenhas et al., 2011). Ainda que frequentemente pouco entendido (e ocasionalmente mal desempenhado), o papel do editor deve ser, primordialmente, o de intermediário entre autor(es) e revisores.

O Quadro 1, adaptado do trabalho de Elson e Brouard (2012), revela um sumário das principais etapas do processo editorial. Genericamente, as etapas incluem desde o planejamento da pesquisa e a redação do artigo, a seleção do periódico e o envio (ou submissão), a avaliação pelo editor e revisores, as interações entre os autores, o editor e revisores, até a decisão final (aceitar ou rejeitar o artigo) e publicação. O processo tem alguns loops, em especial nas etapas de revisão. O quadro também mostra que os três principais agentes são o(s) autor(es), o(s) editor(es) e os revisores. Em seguida descrevemos o essencial dessas etapas.

Revista de Gestão e Secretariado - GeSec, São Paulo, v. 5, n. 2, p 01-22, mai./ago. 2014. 


\begin{tabular}{|c|c|c|c|}
\hline TAREFAS & AUTOR(ES) & EDITOR(ES) & REVISOR(ES) \\
\hline Planejar e fazer a pesquisa & $\mathrm{x}$ & & \\
\hline Selecionar o periódico & $\mathrm{x}$ & & \\
\hline Analisar (ler) as instruções para autores do periódico & $\mathrm{x}$ & & \\
\hline Escrever o artigo & $\mathrm{x}$ & & \\
\hline Apresentar em eventos, universidades, palestras etc. & $\mathrm{x}$ & & \\
\hline Submeter a periódico & $\mathrm{x}$ & & \\
\hline Receber o artigo & & $\mathrm{x}$ & \\
\hline $\begin{array}{l}\text { Tomar a decisão inicial (desk review) } \\
\text { Rejeitar (desk reject) } \\
\text { Solicitar ajustes/revisão antes de enviar para revisores } \\
\text { Enviar para avaliação de revisores } \\
\text { Aceitar (pouco usual) }\end{array}$ & & $\mathrm{x}$ & \\
\hline Receber a rejeição ou solicitação de ajustes & $\mathrm{x}$ & & \\
\hline Ressubmeter para o periódico & $\mathrm{x}$ & & \\
\hline Selecionar os revisores & & $\mathrm{x}$ & \\
\hline Ler, avaliar o artigo, escrever o parecer e enviar parecer & & & $\mathrm{x}$ \\
\hline Receber os pareceres, analisar e consolidar as análises & & $\mathrm{x}$ & \\
\hline Tomar decisões com base nos pareceres e leitura própria & & $\mathrm{x}$ & \\
\hline $\begin{array}{l}\text { Decidir } \\
\text { Rejeitar (fundamentada) } \\
\text { Solicitar revisão com base nos pareceres (pode ser revisão } \\
\text { grande ou pequena) } \\
\text { Aceitar sem modificações (pouco usual) } \\
\text { Aceitar com pequenas modificações } \\
\end{array}$ & & $\mathrm{x}$ & \\
\hline Receber pareceres do editor e dos revisores & $\mathrm{x}$ & & \\
\hline SE REJEITADO - reavaliar artigo & $\mathrm{x}$ & & \\
\hline Analisar pareceres & $\mathrm{x}$ & & \\
\hline Preparar a revisão & $\mathrm{x}$ & & \\
\hline $\begin{array}{l}\text { Ressubmeter o artigo revisado e as cartas ao editor e a cada } \\
\text { um dos revisores com explicação detalhada das alterações }\end{array}$ & $\mathrm{x}$ & & \\
\hline Receber o artigo revisado e as cartas explicativas & & $\mathrm{x}$ & \\
\hline $\begin{array}{l}\text { Analisar as explicações recebidas e alterações efetivamente } \\
\text { realizadas }\end{array}$ & & $\mathrm{x}$ & \\
\hline $\begin{array}{l}\text { Decidir } \\
\text { Rejeitar } \\
\text { Solicitar nova avaliação pelos revisores } \\
\text { Solicitar pequenas modificações adicionais } \\
\text { Aceitar }\end{array}$ & & $\mathrm{x}$ & \\
\hline $\begin{array}{l}\text { Se o editor enviar para nova avaliação: } \\
\text { Analisar as explicações recebidas e as alterações efetivamente } \\
\text { realizadas } \\
\text { Escrever o parecer e enviar ao autor e editor }\end{array}$ & & & $\mathrm{x}$ \\
\hline Receber pareceres, analisá-los e consolidá-los & & $\mathrm{x}$ & \\
\hline Formar opinião com base nos pareceres e leitura própria & & $\mathrm{x}$ & \\
\hline Tomar decisão final & & $\mathrm{x}$ & \\
\hline Receber pareceres dos revisores e editor & $\mathrm{x}$ & & \\
\hline Receber decisão (celebrar se aceito, reavaliar se rejeitado) & $\mathrm{x}$ & & \\
\hline Acompanhar a revisão e edição & & $\mathrm{x}$ & \\
\hline Publicar o artigo & & $\mathrm{x}$ & \\
\hline Disseminar o artigo na comunidade & $\mathrm{x}$ & $\mathrm{x}$ & \\
\hline
\end{tabular}

Quadro 1 - Resumo das etapas no processo editorial Fonte: Adaptado de Elson e Brouard (2012).

Revista de Gestão e Secretariado - GeSec, São Paulo, v. 5, n. 2, p 01-22, mai./ago. 2014. 
Planejar e fazer a pesquisa. Os pesquisadores pretendem sempre publicar suas pesquisas em periódico científico. Não examinamos aqui o tipo de pesquisa realizado, mas importa que os autores entendam que diferentes disciplinas têm diferentes padrões e metodologias dominantes e as dominem. No entanto, é relevante notar que é frequente os periódicos limitarem o número de palavras ou páginas dos artigos que lhes são submetidos. Também diferentes periódicos têm diferentes orientações. Nossa sugestão é considerar estas restrições no momento de planejar a pesquisa e, depois, de redigir o artigo.

Selecionar o periódico. Crescentemente os periódicos se especializam por campos de estudo. Por exemplo, na área de Administração, notamos periódicos dedicados a estratégia, marketing, empreendedorismo, produção, gestão de operações etc. Também alguns periódicos definem o tipo de artigo que esperam receber. Por exemplo, o Academy of Management Review define que publica trabalhos conceituais, ou não empíricos, enquanto o Academy of Management Journal tem como foco a publicação de artigos empíricos. Conhecer o periódico antes de submeter o artigo envolve, ainda, entender sua audiência, porque é provável que os revisores de um artigo submetido sejam membros dessa audiência (Grant \& Pollock, 2011). Assim, sugerimos estudar o periódico, ler alguns artigos, citar artigos publicados nesse periódico e examinar o estilo de escrita e organização dos artigos publicados (Levy \& Grewal, 2007; Serra et al., 2008; Ragins, 2012).

$\mathrm{Na}$ seleção do periódico, é relevante entender os temas que usualmente publica e as metodologias, mas, também, a estrutura seguida para os artigos. Embora não exista um modelo único e universalmente aceito de organizar um artigo, sabemos que há efetivamente bastante uniformidade quanto às partes que devem constar no artigo (sugerimos, para mais detalhes sobre a estrutura de um artigo, que veja Ferreira, 2013a). Mas é necessário atender às diferenças entre artigos e, por exemplo, artigos conceituais e artigos baseados em estudos qualitativos podem diferir substancialmente quanto à estrutura. Assim, recomendamos prestar especial atenção à formalização da questão de pesquisa e ser explícito quanto à contribuição do artigo. A questão de pesquisa, independentemente da metodologia ou do tipo de artigo, é o que deve guiar todo o artigo (Grant \& Pollock, 2011).

Em suma, recomendamos que os autores entendam o periódico e que leiam as diretrizes para autores - que todos os periódicos disponibilizam. No Brasil, para saber quais os periódicos existentes, pode consultar a lista Qualis (disponível em qualis.capes.gov.br/webqualis/).

Escrever o artigo. Aos estudantes de doutorado importa notar que um artigo não deve ser 
um corta-e-cola de seções da tese ou da dissertação, e dificilmente o artigo que entregam para avaliação de uma disciplina estará em condições de publicação num periódico sem alterações adicionais. A este respeito fazemos quatro sugestões. Primeira, mesmo nos artigos que são pedidos como requisito de avaliação de uma disciplina, devemos sempre pensar em conseguir publicá-los no futuro. Segunda, para ter um artigo em condições de submissão são necessárias muitas horas de trabalho e autodisciplina (Ragins, 2012), e talvez mais especialmente de gestão de tempo. Planejar os dias de trabalho e alocar algumas horas para novas pesquisas e leituras e outras horas para reescrever e revisar os artigos que já estão em curso. Terceira, circular seu artigo junto a colegas, professores, orientador, e em conferências, buscando comentários, críticas e sugestões. Aproveitar realmente as sugestões para melhorar o artigo.

Os melhores parceiros são aqueles que analisam seu artigo em profundidade, não aqueles que lhe dizem quão fantástico ele é. A quarta sugestão é que se pretende escrever um artigo a partir da tese, é importante atender a que um artigo é consideravelmente mais curto e que as expectativas de um artigo são diferentes - por exemplo, a revisão de literatura tende a ser muito mais longa numa tese, mas num artigo esperamos uma revisão bem focada e específica face à questão de pesquisa (Reuber, 2010; Craig, 2010). Outra diferença é que um artigo não apresenta objetivos geral e específicos, mas somente uma questão de pesquisa clara e objetiva. É crucial por isso entender a estrutura do artigo e o que é realmente importante na tese que deve ser colocado no artigo.

Submeter ao periódico. Quando um artigo é enviado ao periódico, provavelmente haverá uma mensagem de confirmação da submissão. Embora alguns periódicos ainda não tenham adotado essa prática, ela se torna progressivamente mais comum. Assim, se não receber o e-mail de confirmação, procure saber se o artigo foi recebido. É provável que, se não houver resposta do editor em duas ou três semanas, o artigo tenha sido enviado para avaliação por revisores. O que fazer? Nada. Nesta fase é preciso aguardar pelos comentários dos revisores e a decisão editorial antes de fazer nova submissão a outro periódico, ou antes de fazer mais alterações. Um artigo não pode ser submetido a dois periódicos simultaneamente.

O editor. Após a submissão do artigo ao periódico, uma de quatro alternativas pode ocorrer: (1) o editor pede ajustes adicionais antes de considerar enviar para avaliação, (2) o editor rejeita o artigo e envia aos autores uma carta explicativa da rejeição (que já referimos como sendo um desk reject), (3) o editor envia o artigo a um conjunto de revisores (usualmente entre dois e três) a quem solicita uma avaliação, e (4) o editor decide aceitar o artigo com base na sua própria análise (Radford et al., 1999; Pinho, 2005; Craig, 2010; Ahlstrom, 2010; Braz, 2013). Embora menos comum, aceitar sem revisão pelos pares é uma possibilidade legítima e uma prerrogativa dos

Revista de Gestão e Secretariado - GeSec, São Paulo, v. 5, n. 2, p 01-22, mai./ago. 2014. 
editores.

Os revisores. Os revisores e editores são comumente considerados os gatekeepers do conhecimento (Bedeian, 2004; Starbuck, 2005; Miller, 2006; Harzing \& Metz, 2013) porque a eles cumpre a função de escrutinar os artigos que lhes são submetidos e avaliar seu rigor, contribuição etc. (Gondim, 2004; Mascarenhas et al., 2011). Os revisores recebem uma solicitação de avaliação de um artigo do qual desconhecem o autor, com a indicação de uma data-limite para o envio do seu parecer. Idealmente, os revisores são selecionados por serem conhecedores do campo da pesquisa, das metodologias usadas, ou por algum outro critério que o editor use para identificar os melhores revisores para cada artigo (Braz, 2013). Com base em sua leitura, os revisores escrevem um parecer ao autor apontando o que está bem e, especialmente, o que precisa ser melhorado no artigo. Escrevem, também, uma pequena nota ao editor, informando sobre sua avaliação e com uma recomendação (aceitar, nova revisão necessária, ou rejeitar).

$O$ editor analisa pareceres e decide. Com base nos pareceres dos revisores e na sua própria leitura, o editor toma uma decisão. Há três resultados possíveis nesta etapa: o editor pode aceitar o artigo, pode solicitar alterações ao artigo para nova avaliação pelos revisores ou pode rejeitar. Em todo o caso, enviará uma carta ao autor explicando o que precisa ser feito, à qual junta os pareceres dos revisores (Braz, 2013).

Recebimento da resposta e o que fazer. Se receber uma carta (hoje em dia é um e-mail) do editor aceitando seu artigo para publicação, celebre. É sempre motivo de satisfação ter um artigo aceito para publicação. Mas é possível que receba uma rejeição. Na realidade, vários estudos (ver, por exemplo, Rynes, Hillman, Ireland, Kirkman, Law, Miller, Rajagopalan N., \& Shapiro, 2005; Tsang \& Frey, 2007; Serra et al., 2008; Diniz, 2013; Ferreira, 2013b) indicam que nos principais periódicos internacionais as taxas de rejeição são tão altas - em alguns periódicos superiores a $90 \%$ - que podemos afirmar que a rejeição, e não a aceitação, é a norma. Se for este o caso, não desanime. Poucas coisas podem ser tão destrutivas para o percurso acadêmico de um pesquisador como ver as suas pesquisas rejeitadas. Muitos desistem com a frustração. No entanto, a resiliência e persistência são a chave para o sucesso na profissão.

Uma resposta editorial provável é a solicitação para os autores fazerem modificações no artigo, atendendo às sugestões dos revisores e às do próprio editor, após o que nova rodada de avaliação será feita. Para ter sucesso importa que os autores saibam como agir na revisão e na interação com os revisores. Assim, apontamos algumas sugestões específicas que podem seguir.

Revista de Gestão e Secretariado - GeSec, São Paulo, v. 5, n. 2, p 01-22, mai./ago. 2014. 
Primeiro, não estranhar que diferentes revisores apresentem sugestões e pedem ajustes algo contraditórios (Fisk \& Fogg, 1990) e até difíceis de conciliar numa revisão do artigo. Segundo, não esquecer que, a ressubmissão do seu artigo já revisado deve ser sempre acompanhada por uma carta separada para cada revisor, e uma para o editor, explicando ponto por ponto cada uma das alterações feitas em resposta às sugestões (Spector, 1998; Bedeian, 2003; Tsang \& Frey, 2007). Cada um dos comentários dos revisores deve ser respondido (Spector, 1998) de forma bem explícita. Não é suficiente dizer que uma dada alteração foi feita. Antes, é preciso dar detalhes sobre as modificações feitas ou mesmo reproduzir o texto específico que foi acrescentado ou alterado no artigo, reproduzindo frases, parágrafos ou mesmo seções.

E se não conseguir fazer as alterações pedidas? Neste caso, é importante que a carta ao revisor, ou editor, explique porque essa alteração não é possível. Idealmente a argumentação deverá ser conceitual, não tanto relacionada com limitações empíricas ou da base de dados. No entanto, recomendamos levar muito a sério os comentários dos revisores e dedicar um esforço sério para corrigir os aspectos que os revisores levantam (Levy \& Grewal, 2007). A palavra de ordem é não deixar de fazer as alterações pedidas e, caso não seja possível ou não seja razoável, explicar e argumentar bem.

Os editores também são um agente nesse processo na medida em que recebem o artigo revisado dos autores e as cartas (Tsang \& Frey, 2007) e decidem sobre a continuação do artigo revisado no processo. Às vezes no seu zelo, tomam decisões erradas. Gans e Shepherd (1994) mostram tais erros num levantamento de artigos de economia que foram rejeitados de periódicos e se tornaram fundamentais nos seus campos de estudo.

Divulgação. Uma vez o artigo aceito para publicação, a editora realizará a divulgação pela comunidade e disponibilizará o artigo em bases de dados (Braz, 2013). Mas o autor também pode, e deve, aproveitar as oportunidades para divulgar seu trabalho.

\section{ALGUMAS SUGESTÕES PARA PUBLICAÇÃO}

Exposto que foi o processo editorial, ainda que com a simplificação necessária, focamos agora cinco sugestões específicas para aumentar a probabilidade de publicação. Essas sugestões envolvem entender quem é a audiência, a importância da estrutura do artigo e da qualidade da redação, distinguir o que é revisão de literatura do que é a contribuição ou argumentação própria do autor,

Revista de Gestão e Secretariado - GeSec, São Paulo, v. 5, n. 2, p 01-22, mai./ago. 2014. 


\subsection{QUEM É A AUDIÊNCIA?}

Entender quem é a audiência de um periódico é relevante (Levy \& Grewal, 2007; Ragins, 2012). Com o aumento do número de periódicos disponíveis, também tem aumentado sua segmentação e especialização relativas. Alguns periódicos são claramente orientados para acadêmicos, enquanto outros têm por foco uma audiência de profissionais nas empresas ou no setor público. Pelo menos em parte, muitos periódicos indicam, na sua missão, qual a audiência a que se dirigem e qual seu escopo.

É importante entender quem é a audiência por quatro motivos essenciais. Primeiro, porque o estilo de escrita será substancialmente diferente de acordo com a audiência (Ragins, 2012). Por exemplo, num artigo dirigido a acadêmicos, espera-se uma escrita mais formal, com o uso extensivo de referências a trabalhos anteriores publicados em periódicos de alto status. Em contraste, periódicos dirigidos a profissionais (gestores, executivos) não terão todas estas referências e, mesmo quando estas existem, são frequentemente incluídas com um sobrescrito e a referência surge ou no rodapé ou numa listagem no final. O texto também será menos formal em artigos para profissionais. Ainda assim, mantêm-se algumas expectativas na redação do artigo: (1) a informação é veiculada em frases completas; (2) um parágrafo não é apenas uma frase isolada; (3) a ideia é exposta num artigo com uma estrutura definida; (4) o texto não é apenas um reflexo de uma opinião vaga e os argumentos precisam de alguma evidência (que em artigos para profissionais podem ser exemplos, dados estatísticos, ou casos, mas que em artigos acadêmicos são outros artigos publicados) (Rynes et al., 2005; Ragins, 2012).

Segundo, importa saber quem é a audiência porque é provável que entre a audiência estejam os potenciais revisores do artigo (Tsang \& Frey, 2007). Mesmo os periódicos com maior foco num público de profissionais sujeitam os artigos à avaliação: pode ser apenas uma avaliação pelo editor ou envolver dois ou três revisores. Este é um aspecto importante porque alguns artigos, que não são baseados em teoria ou numa literatura mais sólida (como é o caso deste nosso artigo), ou em dados estatísticos coletados segundo os preceitos instituídos, provavelmente não serão adequados para serem submetidos à avaliação por revisores, mesmo que adequados para publicação em periódico. Os revisores tendem a ter expectativas sobre os artigos que recebem para avaliação em aspectos como: (1) esperam ver uma questão de pesquisa claramente exposta; (2) esperam ver uma contribuição; (3) esperam uma seção de metodologia em que se explicam procedimentos de coleta

Revista de Gestão e Secretariado - GeSec, São Paulo, v. 5, n. 2, p 01-22, mai./ago. 2014. 
de dados, instrumentos de coleta, amostra e procedimentos de análise (Rynes et al., 2005; Craig, 2010), (4) esperam os resultados indicados sem ambiguidade; (5) esperam a interpretação dos resultados.

Terceiro, pelo assunto tratado (Levy \& Grewal, 2007): muitos artigos são rejeitados por não se enquadrarem no foco do periódico (Rynes et al., 2005). Por exemplo, a Gesec tem uma audiência bem definida e com interesses específicos de leitura. No entanto, a Gesec dirige-se tanto para profissionais como para acadêmicos, permitindo assim maior amplitude de artigos publicados - o que também dificulta o trabalho do editor e dos revisores.

Finalmente, entender a audiência é importante para ajustar a forma de escrita. Num periódico para profissionais, a escrita precisa ser ainda mais clara e fluída e os autores não podem assumir conhecimento prévio ou resumir um argumento remetendo para algum outro artigo publicado (Levy \& Grewal, 2007; Ragins, 2012). Também o uso de voz ativa na construção das frases se torna mais relevante, tal como o uso da primeira pessoa (o eu, autor do artigo) ou do impessoal (Ferreira, 2013a) na construção das frases. Na realidade, estas duas dicotomias já não se colocam realmente, porque refletem o contraste entre um modelo tradicional e um modelo moderno. Há uns anos atrás, o uso de um agente, um autor, indefinido era uma forma de "modéstia" e impessoalidade na publicação. Atualmente, também reconhecemos que a escrita ativa e mais pessoal ajuda a ligar o leitor com o artigo e torna a escrita mais fluída, direta, curta e dinâmica (Ferreira, 2013a). Em particular, o uso da voz passiva dificulta entender qual é a ação, quem é o sujeito e quem faz o quê. Em suma, em artigos para profissionais todos os cuidados na redação são ainda mais relevantes para conectar o leitor com as ideias expressas no artigo.

\subsection{A ESTRUTURA DO ARTIGO E QUALIDADE DE REDAÇÃO}

O trabalho científico não vale apenas pelo seu rigor, importância ou relevância (Mascarenhas et al., 2011). Todo trabalho precisa ser comunicado de modo que a comunidade o conheça, entenda e use em trabalhos futuros. O progresso depende da divulgação do conhecimento gerado, e não há progresso com ótimos trabalhos que não saem da gaveta. Comunicar o trabalho científico significa conseguir publicá-lo e, para isso, precisamos atender novamente às normas vigentes de estruturação e de redação (Rynes et al., 2005). É especialmente relevante que estudantes de mestrado e doutorado entendam o que isto significa.

As falhas e falta de clareza na estrutura e na organização do artigo são frequentemente apontadas pelos revisores como um dos motivos que leva à rejeição (Ragins, 2012). Em

Revista de Gestão e Secretariado - GeSec, São Paulo, v. 5, n. 2, p 01-22, mai./ago. 2014. 
Administração, a estrutura comum é a seguinte: capa, resumo, palavras-chave, introdução, revisão da literatura (ou referencial teórico), desenvolvimento conceitual, método, resultados, discussão, conclusões, referências, anexos (Levy \& Grewal, 2007; Craig, 2010). Esta é, pelo menos usualmente, a estrutura que recomendamos seguir, fazendo-se os devidos ajustes face ao tipo de artigo (por exemplo, trabalhos qualitativos ou trabalhos conceituais). Quanto à organização, referimo-nos à sequência dos parágrafos e frases no artigo. Um artigo publicável não é uma sequência de frases truncadas e desconexas que não permitem entender nem qual o objetivo nem a coerência. Se o revisor não entender o texto, é provável que ou rejeite o artigo ou peça para o autor fazer mais alterações do que seria necessário.

Em termos práticos, sugerimos que o autor comece por escrever a estrutura base do seu artigo. O que isto significa é: primeiro, num arquivo MsWord escreva a estrutura fundamental do artigo (capa, resumo, introdução, [...] , referências) (Craig, 2010; Ferreira, 2013a). Em seguida, em cada seção, escreva quais os aspectos fundamentais que precisa transmitir. Cada autor tem seu método, mas o que pretendemos com esta sugestão de começar por estruturar é forçar o autor a pensar qual o conteúdo fundamental do artigo e qual a sequência que esse conteúdo irá surgir no artigo. As vantagens de criar um "sumário" inicial são inúmeras, incluindo evitar repetições e melhorar as transições entre parágrafos e entre seções.

Embora um artigo não seja um romance, também não deve ser um thriller de mistério em que o leitor fica em suspense até ao final para saber o que aconteceu. Todo o artigo deve oferecer uma história que seja clara, direta e atrativa; uma história que atraia a atenção do leitor e que, depois, o mantenha atento do começo ao final (Craig, 2010; Ragins, 2012). Uma boa história começa com uma boa introdução (Grant \& Pollock, 2011; Ragins, 2012). Parte da construção da história está no posicionamento do artigo na literatura e no estabelecimento de sua contribuição (Levy \& Grewal, 2007). Mesmo o desenvolvimento conceitual e as hipóteses devem ser coerentes com a história (Levy \& Grewal, 2007) e estarem ajustados com o todo que é o artigo. Mas isto não é fácil de fazer. Como notou Ragins (2012), o autor precisa conseguir captar a atenção do leitor com uma justificativa clara, atrativa e convincente do artigo.

Revista de Gestão e Secretariado - GeSec, São Paulo, v. 5, n. 2, p 01-22, mai./ago. 2014. 


\subsection{O QUE É NOVO (OU A CONTRIBUIÇÃO) E O QUE É LITERATURA EXISTENTE}

Uma das dificuldades que os estudantes têm prende-se com a conjugação entre o que são as suas próprias ideias e o que é efetivamente revisão da literatura (Craig, 2010; Reuber, 2010). Este não é só um pormenor, pelo que merece aqui uma análise diferenciada. Antes, porém, importa começar por entender que um artigo (ou uma pesquisa) não é um ato de total inovação. As pesquisas acrescentam sobre o conhecimento existente e essa contribuição incremental deve ficar bem expressa no artigo. Pelo menos em parte, esse é um dos objetivos da revisão de literatura, onde o autor mostra como seu trabalho se posiciona no conhecimento já existente - ou seja, na literatura já publicada. Assim, o trabalho não pode parecer desconexo da literatura, de modo que a revisão de literatura precisa ser o mais direcionada possível para a questão de pesquisa (Craig, 2010; Reuber, 2010; George, 2014).

As ideias próprias do autor devem ser expressas como uma argumentação. Mas, o que isso significa na prática? Primeiro, que as ideias se constroem sobre outras já existentes e as citações e referências a outros trabalhos publicados servem a essa função de mostrar o componente incremental a que aludimos. Segundo, que a argumentação necessita de evidência, e a evidência são os artigos que o autor vai referenciar (podem ser, também, dados estatísticos e exemplos). Terceiro, que não precisa concordar com tudo o que foi escrito mas, caso discorde, necessita construir um argumento sustentado na literatura que seja explicativo do que discorda e por quê.

Elson e Brouard (2012) mostraram o dilema com que, sobretudo os estudantes, se deparam: se os seus argumentos concordam com outros trabalhos, então não há novidade, mas se não concordam exatamente com o exposto em outro artigo, então dizem que não há pesquisa sobre o assunto e não referenciam adequadamente. O cerne da questão é que, primeiro, dificilmente um estudante escreve sobre algo que é radicalmente novo (e como mostraram Gans e Shepperd (1994), trabalhos radicalmente novos podem esbarrar nos gatekeepers); segundo, precisa reconhecer que aspectos de alguma forma similares, ou com os quais se consegue estabelecer algum paralelismo, já foram estudados antes.

Talvez a questão mais importante que cada autor deve se colocar ao escrever um artigo desde o começo seja "E então, qual a contribuição deste artigo?" Ou, de outro modo: por que os leitores gostariam de ler o que escrevi? (Levy \& Grewal, 2007; Grant \& Pollock, 2011; George, 2014). É necessário observar se as descobertas são óbvias ou se agregam algo de novo ao conhecimento. Também é necessário observar se as descobertas respondem a alguma questão de pesquisa não resolvida, se resolvem um paradoxo ou se estimulam mais pesquisa na área (Levy \&

Revista de Gestão e Secretariado - GeSec, São Paulo, v. 5, n. 2, p 01-22, mai./ago. 2014. 
Grewal, 2007). Não basta achar que tem uma contribuição, é preciso expressá-la de forma clara e convincente aos leitores.

Salientar a importância de estabelecer qual a contribuição do estudo é bastante relevante para os estudantes de pós-graduação. Alunos de mestrado e doutorado tendem a despender muito tempo e esforço nos detalhes metodológicos de suas pesquisas e muito menos esforço em entender como posicionar a contribuição pretendida. Um trabalho metodologicamente bem executado pode não ter nenhuma contribuição. Assim, embora seja importante dominar as técnicas metodológicas, esse domínio é especialmente relevante se acompanhado por um estudo bem fundamentado na teoria e com uma efetiva contribuição. Para dominar conceitualmente o tema, uma boa forma de começar é fazendo uma revisão da literatura acerca do assunto, porque os artigos da revisão são uma excelente forma de sumariar o domínio conceitual da área e de descobrir novas ideias. Quando desenvolvemos um tema, é também importante estudar as diferentes teorias. Para isso, é essencial ler os artigos seminais e as publicações recentes.

\subsection{RESPONDER AOS REVISORES}

Diversos autores se debruçaram sobre diferentes facetas da interação entre autores, editores e revisores. Por exemplo, Levy e Grewal (2007) apontam que os autores devem aprender com o processo de revisão. Ao integrar os comentários e sugestões dos revisores, o artigo poderá melhorar consideravelmente. Ignorar as sugestões dos revisores é um caminho certo para uma subsequente avaliação negativa (Levy \& Grewal, 2011). Ferreira (2013b), em comentário editorial da Revista Ibero Americana de Estratégia, expôs algumas orientações úteis que os autores podem seguir nas suas respostas aos revisores. Salientamos aqui apenas alguns aspectos que nos parecem essenciais para navegar com sucesso nesta etapa do processo editorial de interação com revisores.

Ao revisar o artigo, importa dar especial atenção aos comentários e sugestões dos revisores. A revisão do artigo deve incidir, essencialmente, sobre os aspectos que os revisores comentaram precisar ser ajustados, corrigidos ou acrescentados. Também é fulcral atender aos principais aspectos levantados pelo editor na sua carta de decisão.

Ao responder aos revisores e ao editor, devemos escrever uma carta separadamente para cada um, detalhando todas as alterações. Na carta ao editor, explicamos também, ainda que sumariamente, as alterações ao artigo em resposta às sugestões dos revisores. Não invulgarmente

Revista de Gestão e Secretariado - GeSec, São Paulo, v. 5, n. 2, p 01-22, mai./ago. 2014. 
essas cartas vão ser mais longas que o próprio artigo. Em termos de organização, a carta de resposta deve sempre indicar cada um dos comentários do revisor, seguida da sua resposta. Ou seja, não é para escolher apenas alguns dos pontos levantados pelos revisores. De igual modo, temos de atender e responder a todos os pontos, mesmo que para dizer que não houve alterações face a um aspecto específico e explicando o porquê (Ragins, 2012). É nossa convicção que a carta de resposta contribui muito para a decisão de aceitação (ou rejeição). Por outro lado, o esforço de escrever a carta de resposta ajuda a entender exatamente como melhorar cada um dos aspectos levantados pelo revisor.

Embora as respostas aos revisores possam ser longas, sugerimos que, dentro do possível, sejam concisas e diretas. Ou seja, quando se alteram apenas algumas frases numa seção, não é razoável reproduzir na carta toda a seção dizendo que foram feitos ajustamentos. Finalmente, sugerimos manter sempre um tom positivo e apreciativo. Mesmo que não concordemos com alguma sugestão, nossa discordância pode ser explicada coerentemente e com fundamento na teoria. Uma revisão do revisor não é um ataque pessoal ao autor, mas apenas uma avaliação de um trabalho escrito.

\subsection{O ARTIGO NÃO ESTÁ PERFEITO}

Provavelmente não há artigos perfeitos e todos os artigos, mesmo os publicados nos principais periódicos internacionais, têm lacunas e falhas. Para os autores é muitas vezes difícil saber quando um artigo está em condições de ser submetido. Não temos uma regra ou roteiro de como o descobrir. No entanto, importa apontar que poucos artigos são publicados como inicialmente submetidos. Como já analisamos, a grande maioria dos artigos passará por um processo de avaliação pelos pares e por uma revisão pelos autores (Bedeian, 2004; Miller, 2006; Raelin, 2008). Muitas vezes este processo de avaliação pelos revisores pode ter duas, três ou quatro rodadas de avaliação e de correspondentes alterações pelos autores. O objetivo deste processo é melhorar o artigo final publicado (Levy \& Grewal, 2011).

Dificilmente um artigo estará pronto para ser submetido em sua primeira versão. Reescrever, reescrever, reescrever, apresentar a colegas, apresentar em eventos, reescrever e reescrever novamente, fazem parte do processo (Levy \& Grewal, 2007; Ferreira, 2013a). Nessas reescritas, a comunicação melhora e as ideias ficam mais fluídas e coerentes com a literatura. O revisor não pode ficar distraído pelos erros ortográficos ou tipográficos (que poderiam ser corrigidos com uma leitura mais atenta ou usando a função de correção de ortografia e gramática do MsWord). O

Revista de Gestão e Secretariado - GeSec, São Paulo, v. 5, n. 2, p 01-22, mai./ago. 2014. 
revisor também não pode ficar distraído por uma escrita descuidada em que os parágrafos não fluam na exposição de uma ideia. Muitos destes eventuais problemas são resolvidos com uma leitura atenta do autor e dos colegas ou professores que façam uma avaliação inicial.

Ainda assim, lembre-se que um artigo excelente na gaveta só será conhecido pela gaveta e pelo autor, mas não pela comunidade. Em algum momento, precisará finalizar o texto (“largar mão") e submeter a um periódico para avaliação. Recorde o que dissemos acima e, antes de submeter, analise as diretrizes e normas que os periódicos disponibilizam para os autores, em especial em termos de formatação das referências, numeração das seções etc. No Brasil é comum os periódicos solicitarem que os autores sigam as normas da ABNT (Associação Brasileira de Normas Técnicas), mas também há periódicos que indicam a APA (American Psychological Association). A última tarefa, possivelmente, será eliminar os dados de identificação do arquivo (no MsWord precisa ir às propriedades do arquivo e eliminar os dados de identificação).

\section{DISCUSSÃO E NOTAS FINAIS}

Não há uma receita para o sucesso na publicação, mas há algumas orientações que os autores podem seguir para aumentar a probabilidade de ter seus artigos aceitos. Apresentamos aqui algumas sugestões e revimos brevemente o processo de submissão a periódicos científicos. É nossa convicção que entender estes aspectos ajudará a ajustar o artigo ao periódico para o qual pretende submeter e, talvez, inclusive, ajudar a planejar a pesquisa de acordo com o periódico desejado. Embora todo o processo possa parecer uma caixa-preta, em que algumas imperfeições parecem desvirtuar a produção acadêmica, todos somos revisores e alguns somos editores que voluntariam seu tempo, esforço e criatividade para auxiliar no processo, de modo que os artigos publicados tenham melhor qualidade. As disfunções aparentes não retiram todo o mérito do processo.

Embora frequentemente os autores critiquem os revisores dos seus artigos - em especial na sequência de uma rejeição (não recordo ter ouvido alguma vez alguém criticar os revisores que aceitaram para publicação um artigo que o não merecia) -, importa entender por que revisamos artigos. Todos os pesquisadores revisam artigos para eventos e periódicos em um momento ou outro. O essencial é que tenhamos consciência de que ser revisor ou autor depende da situação e que somos revisores em algumas vezes, enquanto em outras somos autores. Assim, requer-se que todo o

Revista de Gestão e Secretariado - GeSec, São Paulo, v. 5, n. 2, p 01-22, mai./ago. 2014. 
processo decorra com cortesia e dentro de um espírito construtivo de melhoria e progresso.

Ser revisor para um periódico ou uma conferência é um fardo que retira tempo e foco dos pesquisadores de outras atividades que têm de desempenhar. Mas é, também, um benefício. A este respeito abusamos das ideias de Singh (2003), que apontou alguns benefícios que os revisores têm: acesso ao mais novo conhecimento que está a ser gerado, reconhecimento do trabalho pela comunidade, capacidade de moldar o campo de estudo, sentimento pessoal de contribuição à comunidade, entre outros. O tempo e esforço posto na leitura, análise e redação de pareceres são alimento intelectual (Singh, 2003).

Há ainda muito para entender sobre a forma como o processo editorial decorre em um nível micro. Por exemplo, como os revisores atuam quando recebem um artigo ou como os editores escolhem efetivamente os revisores para cada artigo submetido ao periódico. Entender melhor todo o processo contribuirá para desmistificar mitos e aprimorar as atuações dos agentes (autores, editores e revisores) e a qualidade dos trabalhos. Talvez conhecer o processo auxilie a desvanecer mitos e práticas possivelmente menos adequadas, como quando os orientandos creem que seus orientadores devem ser os primeiros autores nos artigos para conseguir publicar. Entender as competências necessárias para conseguir publicar pode também ajudar os pesquisadores a pensar mais estrategicamente em suas redes de coautoria. Mas talvez seja mais relevante que quase parece haver uma crença que alguns pesquisadores mais prolíficos têm um dom de escrita quando a realidade aponta apenas para esforço, dedicação e perseverança (Gray, 2005).

\section{REFERÊNCIAS}

Acedo, F., Barroso, C., Casanueva, C. \& Galán, J. (2006). Co-authorship in management and organizational studies: An empirical and network analysis. Journal of Management Studies, 43(5), 957-983.

Ahlstrom, D. (2010). Clearing the first hurdle as the Asia Pacific Journal of Management. Asia Pacific Journal of Management, 27(2), 171-177.

Armstrong, J. (1997). Peer review for journals: Evidence on quality control, fairness, and innovation. Science and Engineering Ethics, 3(1), 63-84.

Revista de Gestão e Secretariado - GeSec, São Paulo, v. 5, n. 2, p 01-22, mai./ago. 2014. 
Barabási, A.; Jeong, H.; Néda, Z.; Ravasz, E.; Schubert, A. \& Vicsek, T. (2002). Evolution of the social network of scientific collaborations. Physica A, 311(3), 590-614.

Barnett, A.; Ault, R. \& Kaserman, D. (1988). The rising incidence of co-authorship in Economics: Further evidence. The review of Economics and Statistics, 70(3), 539-543.

Bedeian, A. (2004). Peer review and the social construction of knowledge in the management discipline. Academy of Management Learning \& Education, 3(2), 198-216.

Bedeian, A. (2003). The manuscript review process: The proper roles of authors, referees, and editors. Journal of Management Inquiry, 12(4), 331-338.

Bertero, C. (2007). Editorial. Revista de Administração de Empresas - eletrônica, 6(1), 1-2.

Beyer, J., Chanove, R. \& Fox, W. (1995). The review process and the fates of manuscripts submitted to the AMJ. Academy of Management Journal, 38(5), 1219-1260.

Blackburn, J. \& Hakel, M. (2006). An examination of sources of peer-review bias. Psychological Science, 17(5), 378-382.

Braz, J. (2013). Da submissão à publicação: Como trabalhamos com o seu manuscrito. Journal of the American Chemical Society, 24(6), 891-892.

Byrne, D. (2000). Common reasons for rejecting manuscripts at medical journals: A survey of editors and peer reviewers. Science Editor, 23(2), 39-44.

Craig, J. (2010). Desk rejection: How to avoid being hit by a returning boomerang. Family Business Review, 23(4), 306-309.

Dahdouh-Guebas, F., Ahimbisibwe, J., Van Moll, R., \& Koedam, N. (2003). Neo-colonial science by the most industrialised upon the least developed countries in peer-reviewed publishing. Scientometrics, 56(3), 329-343.

De Meis, L., Velloso, A., Lannes, D., Carmo, M., \& De Meis, C. (2003). The growing competition in Brazilian science: rites of passage, stress and burnout. Brazilian Journal of Medical and Biological Research, 36(9), 1135-1141.

Diniz, E. (2013). Editorial. Revista de Administração de Empresas, 53(1), 1-2.

Revista de Gestão e Secretariado - GeSec, São Paulo, v. 5, n. 2, p 01-22, mai./ago. 2014. 
Elson, P. \& Broudard, F. (2012). Advice for new authors on the submission of articles. Canadian Journal of Nonprofit and Social Economy Research, 3(1), 79-91.

Ferreira, M. (2013a). Comentário editorial: A pesquisa e a estruturação do artigo acadêmico em Administração. Revista Ibero Americana de Estratégia, 12(2), 1-11.

Ferreira, M. (2013b). Comentário editorial: O processo editorial: Da submissão à rejeição (ou aceite). Revista Ibero Americana de Estratégia, 12(3), 1-11.

Fisk, D. \& Fogg, L. (1990). But the reviewers are making different criticisms of my paper. American Psychologist, 45, 591-598.

Frey, B. (2003). Publishing as prostitution? Choosing between one's own ideas and academic success. Public Choice, 116(1-2), 205-223.

Gans, J. \& Shepherd, G. (1994). How are the mighty fallen: Rejected classic articles by leading economists. Journal of Economic Perspectives, 8(1), 165-179.

Geletkanycz, M. \& Tepper, B. (2012). Publishing in AMJ - part 6: Discussing the implications. Academy of Management Journal, 55(2), 256-260.

George, G. (2014). Rethinking management scholarship. Academy of Management Journal, 57(1), $1-6$.

Gondim, S. (2004). A face oculta do parecerista: Discussões éticas sobre o processo de avaliação de mérito de trabalhos científicos. Organizações e Sociedade, 11(31), 195-199.

Grant, A. \& Pollock, T. (2011). Publishing in AMJ - Part 3: Setting the hook. Academy of Management Journal, 54(5), 873-879.

Gray, T. (2005). Publish \& flourish: Become a prolific scholar. New Mexico, Las Cruces, Teaching Academy, New Mexico State University.

Harzing, A. \& Metz, I. (2013). Practicing what we preach. Management International Review, 53(2), 169-187.

Kirschbaum, C. \& Mascarenhas, A. (2009). Nos limites da autonomia: Reflexões sobre o modelo brasileiro de "blind review". Revista de Administração de Empresas - eletrônica, 8(1), Art. 5.

Levy, M. \& Grewal, D. (2007). Publishing perspectives from the editors. Journal of Retailing, 83(3), 247-252. 
Mascarenhas, A., Zambaldi, F. \& de Moraes, E. (2011). Rigor, relevância e desafios da academia em Administração: Tensões entre pesquisa e formação profissional. Revista de Administração de Empresas, 51(3), 265-279.

Miller, C. (2006). Peer review in the organizational and management sciences: Prevalence and effects of reviewer hostility, bias, and dissensus. Academy of Management Journal, 49(3), 425431.

Moody, J. (2004). The structure of a social science collaboration network: Disciplinary cohesion from 1963 to 1999. American Sociological Review, 69(2), 213-238.

Pinho, J. (2005). Brevíssimo manual do editor: Considerações sobre submissão e avaliação de artigos, o papel dos pareceristas e do editor de revistas científicas. Organizações e Sociedade, 12(34), 169-173.

Radford, D., Smillie, L., Wilson, R., \& Grace, A. (1999). Scientific publishing: The criteria used by editors of scientific dental journals in the assessment of manuscripts submitted for publication. British Dental Journal, 187(7), 376-379.

Raelin, J. (2008). Refereeing the game of peer review. Academy of Management Learning \& Education, 7(1), 124-129.

Ragins, B. (2012). Reflections on the craft of clear writing. Academy of Management Review, 37(4), 493-501.

Reuber, A. (2010). Strengthening your literature review. Family Business Review, 23(2), 105-108.

Rutledge, R. \& Karim, K. (2009). Determinants of coauthorship for the most productive authors of accounting literature. Journal of Education for Business, 84(3), 130-134.

Rynes, S., Hillman, A., Ireland, R., Kirkman, B., Law, K., Miller, C., Rajagopalan N., \& Shapiro, D. (2005). Everything you've always wanted to know about AMJ (but may have been afraid to ask). Academy of Management Journal, 48(5), 732-737.

Serra, F., Fiates, G. \& Ferreira, M. (2008). Publicar é difícil ou faltam competências? O desafio de pesquisar e publicar em revistas científicas na visão de editores e revisores internacionais. Revista de Administração Mackenzie, 9(4), 32-55.

Sguissardi, V. \& Silva Jr., J. (2009). Trabalho intensificado nas federais: Pós-graduação e produtivismo acadêmico. São Paulo, SP: Xamã.

Revista de Gestão e Secretariado - GeSec, São Paulo, v. 5, n. 2, p 01-22, mai./ago. 2014. 
Singh, J. (2003). A reviewer's gold. Journal of the Academy of Marketing Science, 31(3), 331336.

Smith, L. (1998). Anonymous review and the boundaries of 'intrinsic merit'. Journal of Information Ethics, 7(2), 54-67.

Sparrowe, R. \& Mayer, K. (2011). Publishing in AMJ - part 4: Grounding hypotheses. Academy of Management Journal, 54(6), 1098-1102.

Starbuck, W. (2005). How much better are the most-prestigious journals? The statistics of academic publication. Organization Science, 16(2), 180-200.

Sugimoto, C., Larivière, V., Ni, C. \& Cronin, B. (2013). Journal acceptance rates: A crossdisciplinary analysis of variability and relationships with journal measures. Journal of Informetrics, 7(4), 897-906.

Swanson, E. (2004). Publishing in the majors: A comparison of Accounting, Finance, Management and Marketing. Contemporary Accounting Research, 21(1), 223-255.

Tsang, E. \& Frey, B. (2007). The as-is journal review process: Let authors own their ideas. Academy of Management Learning \& Education, 6(1), 128-136.

Zhang, Y. \& Shaw, J. (2012). Publishing in AMJ - part 5: Crafting the methods and results. Academy of Management Journal, 55(1), 8-12.

Revista de Gestão e Secretariado - GeSec, São Paulo, v. 5, n. 2, p 01-22, mai./ago. 2014. 